\title{
Experiences of a Newbie Helper in a Free, Open, Online, Mathematics Help Forum Community
}

\author{
Carla van de Sande ${ }^{1}$ \\ ${ }^{1}$ School of Mathematical \& Statistical Sciences, Arizona State University, Tempe, Arizona \\ Correspondence: Carla van de Sande, School of Mathematical \& Statistical Sciences, Arizona State University, \\ Tempe, AZ, 85287. Tel: 1-480-965-3951. E-mail: carla.vandesande@ asu.edu
}

Received: December 15, 2012 Accepted: December 28, 2012 Available online: March 19, 2013

doi:10.11114/jets.v1i1.25

URL: http://dx.doi.org/10.11114/jets.v1i1.25

\begin{abstract}
Free, open, online help forums are open to the public and allow students to anonymously seek homework help from volunteers who have the time, willingness, and experience to respond. These forums offer affordable, accessible, and efficient help given as a social, public endeavor. Some forums exhibit a strong sense of virtual community, especially amongst well-established helpers who are core participants. To investigate how newcomers enter into such activity, five helpers were recruited to participate for eight consecutive weeks in an existing popular forum for mathematics homework help covering arithmetic through advanced mathematics. We explore characteristics of the activity of the newcomer helper who made the most progress in moving from peripheral to fuller participation in terms of membership, influence, and immersion.
\end{abstract}

Keywords: help giving, online forums, networked learning, virtual community, mathematics homework

\section{Introduction}

\subsection{Free, Open, Online, Homework Help Forums}

Free, open, online, homework help forums are found on public websites and allow students to anonymously post queries (often problem-specific questions from assignments) that are then visible to others. These forums are open in the sense that, unlike other asynchronous communication tools (such as course forums or discussion boards), access for students is not restricted to any particular course or institution. Also, instead of hosting discussions based on the content from a particular course, the forums cover broad school subject areas (such as mathematics, science, and business) at a range of course levels (from elementary to graduate). These forums are a help-seeking resource that is currently available to any student who has Internet access.

Students from around the world access these forums when they are in need of help completing assignments or understanding course material outside of the classroom, and this is particularly true for school subject areas such as mathematics that are homework intensive and require students to construct solutions to exercises. It is also probably no coincidence that the mathematics forums receive so much traffic given the large number of students who suffer from "math anxiety" and who approach their studies and math courses with apprehension, if not downright dread. (See Hembree, 1990 for a meta-analysis of the extensive body of research on math anxiety). These are some of the reasons why a mathematics homework help forum was chosen as the focus of this study, although the research presented here is pertinent in any of the school subject areas that help forums cover.

The forums belong to a genre of technology-assisted education called 'networked learning' (Goodyear et al., 2005) that emphasizes the social dimension afforded by information and communications technology. The extent of the 'network' depends, in part, on the participation structure that a given help forum adopts (Martinovic, 2005; Van de Sande \& Leinhardt, 2007). Some forums effectively bound the network by restricting the set of volunteer helpers to those who are qualified according to some criteria (such as content knowledge or pedagogical approach). Other forums favor a broader, self-selecting network (which we refer to as Spontaneous Online Help, or $\mathrm{SOH}$ sites) by allowing any member to take up and respond to a student query and contribute to an ongoing threaded discussion, or thread. What this means is that $\mathrm{SOH}$ "helpers" can be anyone with any level of expertise and favoring any pedagogical approach from anywhere. Furthermore, and paramount to the notion of community, these $\mathrm{SOH}$ helpers can interact with one another in the threads as they collectively help students with their 
assignments.

The helpers (who are generally the core participants) in SOH mathematics forums may exhibit a strong sense of virtual community if they identify with fellow members, assume responsibility for participation, negotiate features and practices, and appear comfortable exchanging ideas (Van de Sande \& Leinhardt, 2007). In such sites, it is common practice for helpers to refer to one another by name, joke and kid around with one another, introduce alternative perspectives or ways of looking at the problem, engage in "math talk," and perform peer review by critiquing or correcting mistakes and errors in others' contributions (Van de Sande, 2008). Broadly speaking, the helpers in forums with these dynamics might be considered as members of a community of practice, as conceptualized by Wenger (1998) and Lave and Wenger (2002).

\subsection{Research Objective}

The objective of this study, which is part of a larger research program investigating online help forums, is to explore the enculturation of newcomer helpers into an SOH mathematics help forum that already has a tightly knit group of well-established helpers. In other words, we are exploring how newcomers learn to become helpers with the goal of helping students learn. Adopting the lingo of contemporary youth particularly with regard to participation in a given Internet activity, we refer to these newcomer helpers as "newbies." Using a modified framework that conceptualizes sense of virtual community, the major question addressed is: What are the characteristics of a newcomer helper who is on an "inbound trajectory" from peripheral to full participation (Wenger, 1998, 100-101) as a helper in such a forum?

\subsection{Theoretical Framework}

A community is chiefly characterized by relational interactions or social ties that draw people together (Heller, 1989). The connections between members of a community need not be based on physical proximity (e.g., neighborhoods or classrooms), but can be forged between people anywhere who share interests, hobbies, or ideas The Internet, in particular, supports such relational communities by mitigating the distance between people who wish to connect and interact with one another.

The notion of a virtual community is a diverse, dynamic, and emergent construct, building largely on our understanding of physical community. According to Fernback and Thompson (1995), a virtual community consists of a set of social relationships created in cyberspace through repeated contact within some boundary. Balasubramanian and Mahajan (2001) specify a set of virtual community requisites: (1) an aggregation of people, (2) rational members, (3) interaction in cyberspace without physical collocation, (4) a process of social exchange, and (5) a shared objective, property/identity, or interest. Preece (1999) emphasizes the relational aspects of a virtual community, such as the presence of mutual support and shared emotional connections. Despite their different emphases, all of these notions of virtual community involve relationships of various kinds (e.g., help services, interest groups, etc.) and degrees (ranging from casual to formal) that exist in Cyberspace.

Like physical communities, virtual communities can be more or less tightly knit. Community researchers refer to the affective bonds that characterize closely woven communities as "sense of community," and recognize that the presence of sense of community increases member satisfaction, commitment, and involvement. Based on McMillan \& Chavaz's (1986) theoretically based and empirically supported descriptive sense of community framework, Koh \& Kim (2003-4) propose three dimensions that characterize a sense of virtual community: (1) membership - people experience feelings of belonging to the community, (2) influence - people feel that they have a voice in the community, and (3) immersion - people are dedicated to spending time within the community. Meaningful antecedents include leaders' enthusiasm (commitment to maintaining and sustaining community) and enjoyability (pleasurable engagement in community activities). In this paper, we apply a modified version of this framework to the activity of a newbie helper on a particular online mathematics help forum to characterize what it means to move from the periphery to fuller participation in a virtual community.

\section{Method}

This investigation is part of a larger study designed to explore and document the enculturation experience of newbie helpers in an existing site with a strong sense of virtual community. This forum already has several well-established helpers as core participants and tolerates a variety of pedagogical tactics (ranging from providing solutions to scaffolding moves). As a first step, we apply qualitative methods because the exploratory research involves an emergent phenomenon (e.g., forum helper enculturation), and is geared toward gaining in-depth information that is difficult to quantify (e.g., group membership) (Strauss \& Corbin, 1990).

Five recruited helpers were asked to participate in an online mathematics SOH forum for at least 10 hours weekly (scheduling flexible) for eight consecutive weeks and were compensated \$10/hour. These (admittedly 
somewhat arbitrary) conditions were intended to support a level of commitment that would be sufficient for participants to become acquainted with the logistics of forum participation and potentially establish themselves as members of the community.

\subsection{Site Description}

Started in 2002 by an enterprising high school sophomore, www.freemathhelp.com (FMH) has attracted over 17,000 members to date, who have contributed upwards of 140,000 posts to more than 34,000 threads. The math help message board is split into individual) forums covering mathematics from the elementary level (arithmetic) up through university (post-calculus), and also includes forums for discussing administrative issues (such as any problems encountered or suggestions for improvement) and "math odds and ends" (puzzles, clever math jokes, trivia, etc.). FMH is an SOH site, so that any registered member can act as a helper. The FMH helpers who volunteer information about themselves as part of their member profile are self-reportedly (retired) educators, professionals, and (advanced) students, who have a passion for wanting to share their expertise and help others. In contrast to some other mathematics help forums, there is no single community advocated pedagogical approach prescribing what it means to "help" and how this should be accomplished, although the dominant perspective is that it is better practice to scaffold students by asking them questions or giving hints rather than to provide answers or worked solutions. (See Van de Sande 2010, 2011 for discussion of a mathematics homework help forum that favors one particular theory of learning.) Instead, on FMH, participating helpers can choose whether and how to respond to any given student query or ongoing thread - and neither these decisions nor the quality of their contributions affect a helper's status on the forum. Instead of having a reputation system (in which status on the forum depends on others' ratings), members (whether they ask questions, answer them, or both) achieve status on the forum according to the number of distinct threads to which they have contributed: new (0-49), junior (50-249), full (250-999), senior (1000-2499), elite (more than 2500). The established helpers on this site convey a sense of virtual community through their dedication (both in terms of regular contributions and longstanding membership) and enjoyment (in helping students as well as in connecting and exchanging ideas with like-minded subject enthusiasts).

\subsection{Participant Characteristics}

Each of the five participants in the larger study had considerable mathematical expertise and experience helping (undergraduate) students solve exercises face-to-face, but was a newbie in online help forum participation. Participants were recruited through advertisement, and selected on the basis of enthusiasm, commitment to the study, and life experience. In particular, an effort was made to recruit young adults who were currently students themselves, as well as adults with career experience. Two of the participants were upperclassmen undergraduate engineering majors (young adults), two were graduate engineering master's students close to completion of their degrees (young adults), and one was a former instructor (adult) with an engineering degree who had recently (6 months previously) immigrated to the United States from Mexico. This last participant was a newbie to the forum in two additional ways: language (English was his second language) and culture (his experiences as a student and instructor took place in Mexico). At the time of the study, the two undergraduate students were also employed part-time by the engineering help center on the campus of a large university in the southwest.

\subsection{Data Sources}

Four sources of data were collected: archived forum threads or logs, interviews, journal entries, and private messages. The primary data source consisted of the logs of participants' threads during their eight contiguous weeks as helpers. In addition, each participant was interviewed twice, once prior to participation, and, again following the eight weeks of participation. These interviews were recorded and transcribed, and addressed content knowledge, experience as helpers/tutors, pedagogical views, comparisons of face-to-face vs. online help, and perceptions of the activity, including suggestions for improvement. To further coordinate the content of forum threads with participants' reflections and intentions, participants were asked to keep journals during the study recording their thoughts, scratch work, and any significant events or encounters. Finally, some of the participants engaged in private messaging with students, which is a forum option. Although not all of these messages were kept (due to lack of foresight on the researchers' part), those that were provide a source of behind the scenes data that is normally not accessible to forum observers.

\section{Results}

Table 1 shows the number of threads and posts for each participant during their eight-week period, as well as the percentage of those threads to which the participant and other helpers contributed. 
Table 1. Amount of participant activity on forum

\begin{tabular}{llccc}
\hline Participant & Educational status & Number of threads & Number of posts & \% of threads w/ other helpers \\
\hline JuicyBurger & UG & 48 & 96 & $77 \%$ \\
JeffWest & UG & 34 & 48 & $76 \%$ \\
tutor_joel & G & 94 & 156 & $64 \%$ \\
swaroop & G & 30 & 31 & $93 \%$ \\
garf & I/ESL & 69 & 75 & $90 \%$ \\
\hline
\end{tabular}

${ }^{1}$ Undergraduate (UG), Graduate (G), Instructor/English as Second Language (I/ESL)

In this paper, we focus our attention on JuicyBurger who, of all the study participants, appeared to make the most progress in moving from peripheral to fuller participation. Although he did not contribute to the largest number of threads nor have the largest number of posts, his activity over the eight weeks was consistent with sharing in a sense of virtual community according to the three dimensions in the Koh \& Kim (2003-4) framework: membership, influence, and immersion. Figure 1 contains our hypothesized schematic depiction of how these dimensions were related to characteristics of Juicy Burger's activity on the forum. We suggest that conforming to the actions of others and affirming the contributions of others are markers of membership, that challenging others demonstrates perception of influence in the community and, conversely, that being either challenged or affirmed by others demonstrates that the community is seeking to influence the member, and, finally, that when a member indicates that $\mathrm{s} / \mathrm{he}$ is actively participating in the joint effort of other members and is also engaging in extracurricular activities that this signals immersion in the virtual community.

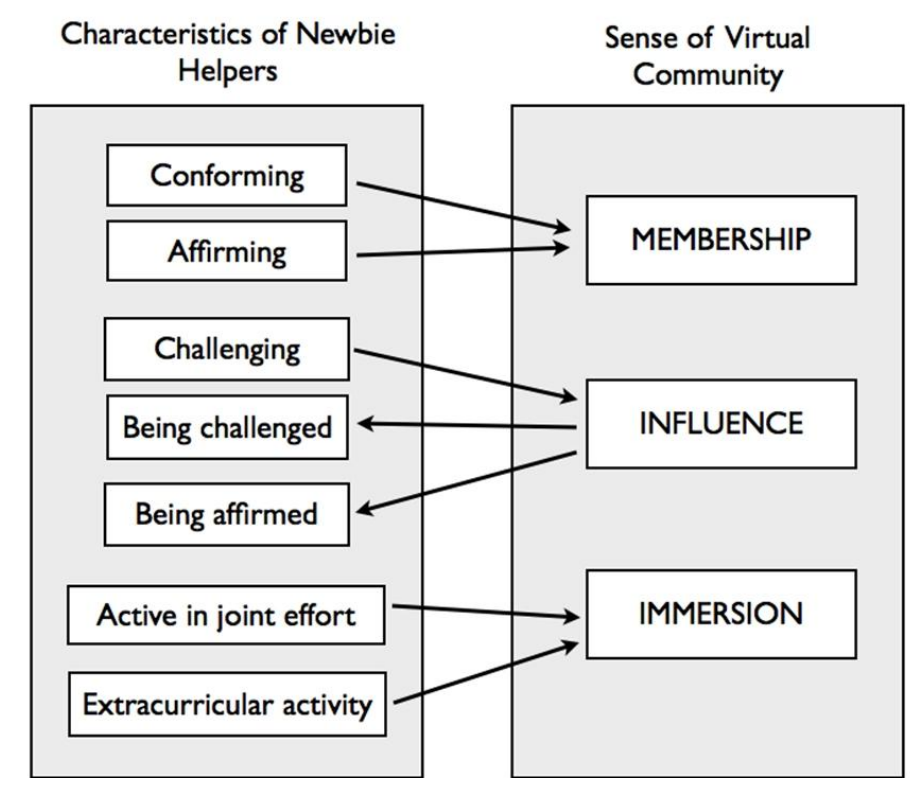

Figure 1. Schematic of relationship between characteristics of newbie helper activity and sense of virtual community

\subsection{Membership}

Members in a virtual community feel connected with other members and enjoy a feeling of belonging, somewhat akin to being a part of a family or a group of close friends. This is true of the established FMH helpers, and evident in the appearance of their contributions, as well as in the ways in which they joke around, tease one another, and compliment one another on clever or novel ways of approaching a problem (Van de Sande \& Leinhardt, 2007). Although the predominant (and perhaps sole) form of interaction amongst most FMH helpers is on-line, there is nevertheless a strong sense of camaraderie and respect for other subject enthusiasts who are seriously engaged in this grassroots effort to band together and help students.

In his forum participation, JuicyBurger consistently communicated a desire to conform or blend in with other helpers, both in the way he presented his contributions and in the way he interacted with others. First, during his 
first week on the forum, he adopted the preferred method of posting mathematical expressions. Using horizontal notation can make it cumbersome to communicate mathematical ideas, and many of the established helpers are proficient at using LaTeX (a typesetting system designed for the production of technical and scientific documentation) to format their contributions. (Students, on the other hand, appear to stick with horizontal notation, perhaps due to their more peripheral participation in the community.) During his first week on the forum, JuicyBurger asked for advice on how to embed math in his posts, took the advice of the senior member who responded, and subsequently used LaTeX to create well-formatted contributions, some of which included quite complicated expressions. In the post-interview, JuicyBurger explained how he was able to quickly "learn" LaTeX by finding and copying (cutting and pasting) examples from experienced helpers' threads and then revising the code for his purpose.

In addition to making his posts look like those of established helpers, JuicyBurger was friendly and congenial, bantering with other helpers, as well as recognizing and affirming others' contributions. Table 2 contains excerpts from JuicyBurger's logs in which he demonstrated solidarity with other helpers by voicing agreement, paying compliments, and supporting their efforts. Notice that in all of these examples, JuicyBurger personalized the interaction by explicitly naming the helper whose contribution he was affirming. By conforming to the habits of established helpers and affirming others' contributions, JuicyBurger signaled to the established helpers that he wished to share membership in their virtual community.

Table 2. Excerpts in which JuicyBurger affirmed and supported contributions made by established helpers.

\begin{tabular}{|c|c|}
\hline Context & $\begin{array}{c}\text { Affirmation } \\
\end{array}$ \\
\hline $\begin{array}{l}\text { JuicyBurger and mmm4444bot (Elite Member) were } \\
\text { collectively working with student who was trying to } \\
\text { graph a parabola in an online system. (posts 1-17) }\end{array}$ & $\begin{array}{l}\text { 'I am with mmm4444bot on this one...' (post } 18 \text { in } \\
\text { thread) }\end{array}$ \\
\hline $\begin{array}{l}\text { BigGlenntheHeavy (Full Member) pointed out to } \\
\text { student who is taking limit of function that the } \\
\text { lower order terms 'become superfluous.' (post } 2 \text { in } \\
\text { thread) }\end{array}$ & $\begin{array}{l}\text { 'BigGlenntheHeavy is correct... You only need to } \\
\text { divide the coefficients of the highest order } \\
\text { term...'(post } 3 \text { in thread) }\end{array}$ \\
\hline $\begin{array}{l}\text { JuicyBurger informed student who was seeking 'an } \\
\text { easier method' for finding arc length, 'I'm sorry to } \\
\text { inform you that this is the only way to do it!' and } \\
\text { suggested that 'the only easier way would be to use } \\
\text { your calculator to integrate for you.' (post } 2 \text { in } \\
\text { thread) }\end{array}$ & $\begin{array}{l}\text { 'Ah hah! That does make it much simpler. Thanks } \\
\text { galactus.' (post } 5 \text { in thread) }\end{array}$ \\
\hline \multicolumn{2}{|l|}{$\begin{array}{l}\text { Galactus (Elite Member) then sketched a method in } \\
\text { which the integral is framed in terms of the } \\
\text { independent variable instead, with the result that 'the } \\
\text { integral is easier.' (post } 4 \text { in thread) }\end{array}$} \\
\hline $\begin{array}{l}\text { mmm4444bot provided student with rules for } \\
\text { logarithmic sums and differences (post } 2 \text { in thread) }\end{array}$ & $\begin{array}{l}\text { 'Now use the rule that mmm4444bot posted for } \\
\text { adding logs and you should find your answer.' (post } 3 \\
\text { in thread) }\end{array}$ \\
\hline
\end{tabular}

\subsection{Influence}

Members of a virtual community feel influential if their contributions are taken up, reviewed by, and responded to by others. In terms of taking up ideas, established FMH helpers often work collectively with a student by continuing a dialogue established by another helper, adding to one another's ideas, and pointing out alternative solutions (Van de Sande, 2008). Because of the nature of the forum (as a help service), reviews often involve challenging, and sometimes correcting, others' posts or self-correcting, which has been referred to as a "Wikipedia-like" quality (Van de Sande \& Leinhardt, 2007) because it represents a collaborative constructive activity with a quest for accuracy. Accordingly, established FMH helpers may have occasional spats that involve challenging the accuracy of one another's mathematics, disagreeing with mathematical approaches (e.g., whether a certain method is necessary or elegant), and criticizing pedagogical tactics (such as providing the student with 
a worked solution). Positive mutual influence on others in the community is demonstrated when criticism and contributions are responded to in an affirmative manner, worked through, and resolved.

\subsubsection{Having Contributions Affirmed}

JuicyBurger's contributions did not go unrecognized by the established helpers. Table 3 contains excerpts from JuicyBurger's logs in which other helpers affirmed his contributions by crediting him by name for correct contributions, taking up and adding onto his helper moves, and supporting his mathematics. The play on words that mmm4444bot (Elite Member) used when referring to one of JuicyBurger's contributions (row two) is further evidence of how other members of the community facilitated his shift to fuller participation.

Table 3. Excerpts in which JuicyBurger's contributions were affirmed and supported by established helpers.

\begin{tabular}{|c|c|}
\hline Context & Affirmed Contribution \\
\hline $\begin{array}{l}\text { JuicyBurger was working with a student to identify } \\
\text { key features in order to graph a parabola. The student } \\
\text { questioned his help, and mmm4444bot picked up the } \\
\text { thread. (posts } 1-4 \text { in thread) }\end{array}$ & $\begin{array}{l}\mathrm{mmm} 4444 \text { bot (Elite Member): 'JuicyBurger is } \\
\text { correct. There is symmetry about the vertical line } \mathrm{x}= \\
-1 . \text { ' (post } 5 \text { in thread) }\end{array}$ \\
\hline $\begin{array}{l}\text { JuicyBurger provided a hint to student that, in order } \\
\text { to find the center and radius of a given circle, the } \\
\text { formula should be converted to the 'standard } \\
\text { equation' }(x-h)^{\wedge} 2+(y-k)^{\wedge} 2=\mathrm{r}^{\wedge} 2 \text { (post } 3 \text { in thread) }\end{array}$ & $\begin{array}{l}\text { mmm4444bot (Elite Member): 'I'll contribute a little } \\
\text { free sauce, to the juicy burger below. [quoted hint } \\
\text { given by JuicyBurger] by completing the square in } \\
\mathbf{x} \text { and y.' (post } 4 \text { in thread) [the bold text was added } \\
\text { onto JuicyBurger's contribution] }\end{array}$ \\
\hline $\begin{array}{l}\text { JuicyBurger was helping student but questioned the } \\
\text { accuracy of his own response: 'Now you } \\
\text { have... [derived expression] What is this equal to? } \\
\text { Hmmm this doesn't seem right.' (post } 2 \text { in thread) }\end{array}$ & $\begin{array}{l}\text { galactus (Elite Member): 'You're [JuicyBurger] on } \\
\text { the right track. This is basic relativity. ...' (post } 3 \text { in } \\
\text { thread) }\end{array}$ \\
\hline
\end{tabular}

\subsubsection{Having Contributions Challenged}

Of course, not all of JuicyBurger's contributions deserved, and therefore received, affirmation; his contributions were also reviewed and challenged when they contained errors. However, as reported in his interview, JuicyBurger generally took his time framing his contributions (for example, by working through solutions on scratch paper before publishing hints and suggestions), and, perhaps for this reason, did not receive many challenges. One of the earlier challenges to JuicyBurger's contributions came in his first week on the forum from mmm4444bot (Elite Member) when he incorrectly took the square root of an expression: 'Juicy Burger forgot that the square root of $(x+6)^{\wedge} 2$ is not $x+6$. It's the absolute value of $x+6$.' JuicyBurger responded in a manner and with a tone consistent with forum practice; he (sheepishly) acknowledged his mistake ('Yes I forgot the +/[confused emoticon]') and edited his earlier post to correct the error.

\subsubsection{Challenging Others' Contributions}

In addition to having his own ideas taken up and challenged, JuicyBurger made efforts to create a voice on the forum by challenging others' contributions, even those of high status members. As is generally FMH practice, he was usually polite (by forum standards which appear to have a higher tolerance for sarcasm and impertinence than face-to-face communications) when he questioned others' contributions. For instance, when galactus (Elite Member) incorrectly parameterized two planes, JuicyBurger simply provided the correct solution for the student (who had also questioned galactus' response), noting the nature and location of the error: 'This should give you: $\mathrm{z}=\mathrm{t}-1($ not $\mathrm{z}=-\mathrm{t}+1)$ [which is how galactus had erred].' Galactus responded with an apology and an edit of his previous response: 'Sorry, that was a typo. I fixed my foolish error. Thanks. Goes to show you, one little negative sugn [sic] misplaced and it's all kaput. [smiling emoticon]' This exchange occurred in the first week following JuicyBurger's forum debut, and served as a model for how members can constructively influence one another as they work collectively to provide correct mathematical help for the students.

JuicyBurger also confronted an established member whom he felt interfered with a dialogue he was trying to establish with a student. The student had requested help finding the area between two curves, and JuicyBurger suggested that the student start by finding the points at which the curves intersected. Fifteen minutes later, BigGlenntheHeavy (Full Member) essentially provided the solution to the problem by posting the resulting 
integrals (which contained the intersection points) together with the final numerical answer, 937/6. JuicyBurger responded within minutes by chastising BigGlenntheHeavy, as shown in Figure 2.

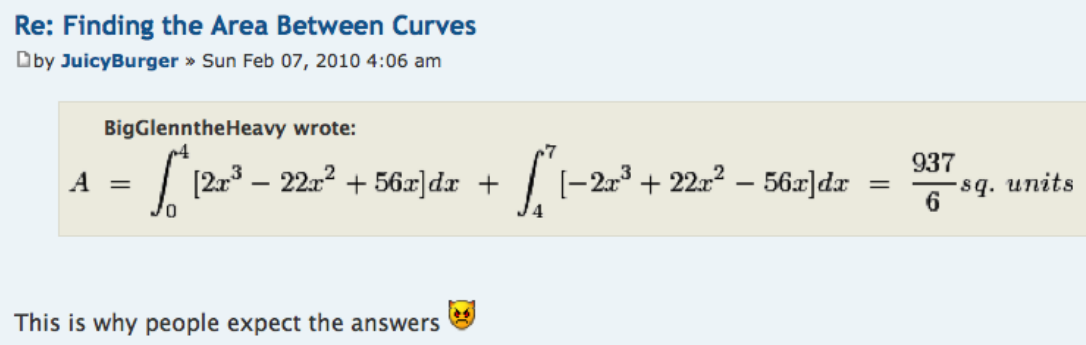

Figure 2. JuicyBurger challenges established FMH helper

In reply, BigGlenntheHeavy defended his actions, perhaps under the impression that JuicyBurger was referring to his giving away the final numerical answer: 'JuicyBurger: It is setting up the problem that requires skill, as the answer then is academic.' Later in the exchange, mmm4444bot (Elite Member) championed JuicyBurger: 'I think that it is obvious that Juicy Burger was not thinking 937/6 when writing "expect the answers". If you claim that setting up the integrals requires the greater skill, big guy, then why aren't you helping to guide the original poster through that process versus spoon-feeding' [italics in the original]. This mentoring move shows how JuicyBurger's voice was validated from an influential member of the community. In the interview, JuicyBurger spoke of this incident, reporting that it contributed to his confidence amongst the 'old guys who control it [the forum].'

Members who share a sense of virtual community exercise influence within the community. In a help forum, this plays out in challenging others' contributions to order to have an influence on the content or material that the students are receiving. Conversely, if a member is influential in the community, then other members pay attention to her/his contributions so that they do not go unnoticed or ignored. Other members may indicate that a member is influential by heeding her/his contributions and responding with either challenges or affirmation.

\subsection{Immersion}

Members are immersed in a virtual community if they are dedicated (or even perhaps addicted) to the activity and spend large amounts of time engaged in interaction. Although we cannot determine the amount of time per se that established FMH helpers spend crafting and publishing responses, their activity level on the forum demonstrates behavior along these lines that is consistent with immersion in the community. Table 4 shows the activity level of the most active FMH helpers during the eight week period, as measured by their number of posts and threads to which they contributed. Given the thought, time, and effort that is required to frame and format math help responses (especially those involving advanced topics), these numbers are impressive. It is also worth noting that JuicyBurger, with his 96 posts in 48 threads over the course of the study, ranks just under these established FMH helpers.

Table 4. Activity count during eight-week study period for well-established FMH helpers

\begin{tabular}{lcccc}
\hline \multicolumn{1}{c}{ Helper } & Member Since & $\begin{array}{c}\text { Status } \\
\text { on 4/10/10 }\end{array}$ & Threads (n) & Posts (n) \\
\hline Mmm4444bot & 2005 & Elite & 288 & 471 \\
Denis & 2004 & Elite & 154 & 195 \\
BigGlenntheHeavy & 2009 & Full & 104 & 163 \\
Subhotosh Khan & 2007 & Elite & 112 & 153 \\
Galactus & 2005 & Elite & 75 & 107 \\
Mrspi & 2005 & Senior & 83 & 102 \\
\hline
\end{tabular}

However, there are other ways, aside from time spent participating and number of contributions, which signal immersion in a virtual community. These may include demonstrating concern by taking seriously the joint efforts of community members, and signaling interest by participating in extra-curricular activities. In other words, the interest with which a member participates may also be used as part of the index for immersion. 


\subsubsection{Joint Effort}

Helpers in an online forum elect how many times they participate in a given thread. Having contributed to a thread, a helper may choose to return to that thread and contribute further, or may choose not to return. In FMH, well-established helpers generally return to threads multiple times, especially if they are involved in an ongoing dialogue with the student or others. This activity demonstrates that helpers have a sense that helping does not consist of a single contribution but rather a process in which they are actively involved.

JuicyBurger appeared to share this view of helping. Instead of participating just one single time in a given thread (as was more the case with other participants in our study), JuicyBurger returned to $46 \%$ of the threads in which he was helping a student. In the interview he reported that he set the forum notification system to inform him when there was further activity in one of the threads in which he was participating so that he might consider whether he could (or should) contribute more. This behavior demonstrates a sense of concern, and perhaps responsibility, for the outcome of his contributions to the community that mimicked the activity patterns of well-established helpers.

Along these same lines, JuicyBurger also allowed students to private message him (an option for forum members), and responded when asked specifically to help them. For instance, one student sent the following private message: 'sorry, my first part of the question was cut-off, I had asked you to help me, cause the other night you did help me, and someone else is trying to help, but I'm so lost. [smile emoticon]' We see here that JuicyBurger identified with the community effort through giving others ways of gaining his attention outside of the forum archives.

\subsubsection{Extracurricular Activity}

Aside from the quantity, consistency, and thoughtfulness of the help they provide, the immersion of FMH helpers in this community is evident from their lively participation in extra-curricular activities, such as contributing ideas to the administrative forum and posing and solving math puzzles in the 'math odds and ends' forum. Not only do the established members care about sustaining and improving the quality of FMH, they also appear to greatly enjoy matching wits with other subject enthusiasts and tackling challenging problems.

JuicyBurger participated in three threads in the 'math odds and ends' forum during the study. Although he did not initiate any puzzles and riddles, he challenged others' contributions, contributed his ideas for solutions, and spent time engaging in deep thought. The most notable example of this was in a 'math odds and ends' thread involving finding the volume of a drilled sphere. JuicyBurger first challenged the framing of the puzzle ('Actually, you do need to know more information. You need to at least know the radius of the sphere.'), but then retracted his challenge just minutes later ('Actually, I think I may be mistaken (=D) I'm still working it out...'). Although JuicyBurger continued working on this puzzle for the next few days, he did not post further in the thread; another forum member, however, did contribute a solution. A week after JuicyBurger had last posted, BigGlenntheHeavy (Full Member) published a calculus-based solution to the puzzle, directing his remarks specifically to JuicyBurger: 'Juicy Burger, in regards to mmm4444bot.'s [sic] poser, if we observe the great circle of a sphere...[solution to puzzle] Note: The volume is independent of $\mathrm{R}$ [the radius of the sphere].' The genuinity of the thought that JuicyBurger put into this puzzle was evident in his reply: 'BigGlenn: Yes I realized this after I posted the statement about it being a large sphere with a large cylinder cut out, or a small sphere with a small radius cylinder. I thought about it a bit more (tempted to google it the entire time) and decided that the question had to make sense, otherwise it would not be riddle. So if the question made sense, it must not depend on the radius, which was when I came up with 36pi. I haven't posted merely because others have already answered it in the in between time whilst I was thinking about it...' We see here that JuicyBurger forewent the easier path (Internet search) in favor of thinking through the problem himself and immersing himself in the type of activity that other forum helpers enjoy. In the interview, JuicyBurger described this problem as 'cool,' noting that he had learned some mathematics from this particular interaction.

We are not claiming here that JuicyBurger became fully immersed in forum participation. He did not become hooked, and ended his participation after the eight-week period. This outcome is not surprising, though, since he was a full-time student. Also, he and the other participants were recruited and paid, which undoubtedly affected their attitude towards the activity. As can be seen in Table 4, many of the established FMH helpers have remained members for several years. On the other hand, we are suggesting that JuicyBurger's behavior during his eight week stint was consistent with becoming immersed in this community, and that this process manifested itself in a variety of ways (aside from simply time spent participating on the forum). Immersion can be marked by active engagement in the joint community effort and by demonstrating enthusiasm for interests shared by other members. 


\section{Discussion}

Free, open, online, help forums represent the movement to democratize education through technological innovation (Larreamendy-Joerns \& Leinhardt, 2006), as well as the increasing relevance of social networks in learning and instruction (Goodyear et al., 2005). The forums provide students around the world with affordable (free), efficient, and accessible help when and where they need it. Students who might not otherwise have access to resources outside of the classroom have the opportunity to ask questions of more experienced others. At the same time, the forums are a unique location where helpers, who traditionally operate individually and privately, can practice alongside others within a community. These helpers work collectively to establish a shared sense of what it means to help students (e.g., providing students with hints versus worked solutions) and to man the forum so that student questions do not go unanswered. Although these helpers may very well not know each other personally, they may become "friends" through their shared commitment to and voluntary participation in the forum. When the existing set of core established helpers form a closely-knit social group, newcomers, who are necessary for the growth and sustainability of the endeavor, must be able to ease their way into the community in order to become core participants. This paper addressed how a newbie helper navigated a trajectory from peripheral to fuller participation in a mathematics help forum with a strong sense of virtual community, learning how to work alongside established members as they helped students learn. Instead of simply hinging on a large quantity of contributions, this process involved cultivating a sense of belonging and building supportive relationships with others (membership), contributing meaningfully and creating a voice (influence), and demonstrating dedication to the shared purpose of the community (immersion).

The larger goal of our research program is to understand online forums as an emergent public resource for learning that is transforming help seeking in the digital age. We see the potential for these online help forums to develop into communities that provide an invaluable service for society, namely helping students everywhere with their homework assignments. The fact that many online help forums are staffed by volunteers is icing on the cake - there are people out there who are willing to invest their time, energy, and attention to building these communities. In order to be a sustainable endeavor, however, people need to continue joining and contributing to these help forums. Therefore, beyond understanding what motivates people to become community builders in the first place (Butler, Sproull, Kiesler, \& Kraut, 2007), we want to characterize the process by which new members become legitimate participants in these communities that are changing the face of help seeking for today's students.

\section{References}

Balasubramanian, S., \& Mahajan, V. (2001). The economic leverage of the virtual community. International Journal of Electronic Commerce, 5, 103-138.

Butler, B., Sproull, L., Kiesler, S., \& Kraut, R. (2007). Community effort in online groups: Who does the work and why? Human-Computer Interaction Institute. Retrieved from http://repository.cmu.edu/hcii/90

Fernback, J., \& Thompson, B. (1995). Virtual communities: Abort, retry, failure? Computer Mediated Communication and the American Collectivity. Retrieved from www.rheingold.com/texts/techpolitix/VCcivil.html

Goodyear, P., Jones, C., Asensio, M., Hodgson, V., \& Steeples, C. (2005). Networked Learning in Higher Education: Students' Expectations and Experiences. Higher Education, 50, 473-508. http://dx.doi.org/10.1007/s10734-004-6364-y

Heller, K. (1989). Return to community. American Journal of Community Psychology, 17, 1-15. http://dx.doi.org/10.1007/BF00931199

Hembree, R. (1990). The nature, effects, and relief of mathematics anxiety. Journal for Research in Mathematics Education, 21, 31-46. http://dx.doi.org/10.2307/749455

Koh, J., \& Kim, Y. G. (2003-4). Sense of virtual community: A conceptual framework and empirical validation. International Journal of Electronic Commerce, 8, 75-93.

Larreamendy-Joerns, J., \& G. Leinhardt (2006). Going the distance with online education. Review of Educational Research, 76, 567-605. http://dx.doi.org/10.3102/00346543076004567

Lave, J., \& Wenger, E. (2002). Legitimate peripheral participation in communities of practice. In M. R. Lea \& K. Nicoll (eds.), Distributed learning: social and cultural approaches to practice (56-63). London: Routledge-Falmer.

Martinovic, D. (2005). Characteristics of asynchronous online mathematics help environments: Do they provide 
conditions for learning? Proceedings of the 12th International Conference on Artificial Intelligence in Education, Workshop 6 Representing and analyzing collaborative interactions: What works? When does it work? To what extent? (pp. 32-38). Amsterdam, the Netherlands.

McMillan, D. W., \& Chavaz, D. M. (1986). Sense of community: A definition and theory. Journal of Community Psychology, 14, 6-23. http://dx.doi.org/10.1002/1520-6629(198601)14:1<6::AID-JCOP2290140103>3.0.CO;2-I

Preece, J. (1999). Empathic communities: Balancing emotional and factual communication. Interacting with Computers, 12, 63-77. http://dx.doi.org/10.1016/S0953-5438(98)00056-3

Strauss, A., \& Corbin, J. (1990). Basics of qualitative research: Grounded theory procedures and techniques. London: Sage.

Van de Sande, C. (2008). Open, online, calculus help forums: Learning about and from a public conversation. (Unpublished doctoral dissertation). University of Pittsburgh, PA.

Van de Sande, C. (2010, June). Free, open, online, mathematics help forums: The good, the bad, and the ugly. In K. Gomez, L. Lyons, \& J. Radinsky (Eds.), Learning in the Disciplines: Proceedings of the $9^{\text {th }}$ International Conference of the Learning Sciences (ICLS 2010) - Volume 1, Full Papers, pp. 643-650, Chicago, IL: International Society of the Learning Sciences.

Van de Sande, C. (2011). How are students' problems being solved? The quality of worked solutions on a popular, open, online, mathematics help forum. In Spada, H., Stahl, G., Miyake, N., Law, N. (Eds.) Connecting Computer-Supported Collaborative Learning to Policy and Practice: CSCL2011 Conference Proceedings. Volume I - Long Papers. International Society of the Learning Sciences, pp. 280-287.

Van de Sande, C., \& G. Leinhardt. (2007). Online tutoring in the Calculus: Beyond the limit of the limit. Éducation et Didactique, 1(2), 115-154.

Wenger. E. (1998). Communities of practice: learning, meaning and identity. New York: Cambridge University Press.

\section{$(\mathrm{cc}) \mathrm{BY}$}

This work is licensed under a Creative Commons Attribution 3.0 License. 